\title{
Sobre una estrategia topicalizadora del español
}

\section{Introducción}

En este trabajo se propone que en español la función informativa de tópico se puede codificar mediante una estructura gramatical en la que un grupo nominal indefinido (ya sea indeterminado, ya esté introducido por el indefinido un/a/os/ as) es modificado por una oración de relativo restrictiva con contenido remático o focal. Los ejemplos siguientes ilustran la construcción:

(1) a. A mi derecha, don Pierino Germini, sesenta y seis años, sacerdote, es italiano es fundador de las comunidades Encuentro, unas comunidades que acogen a drogadictos y a enfermos de sida. (Oral, A debate, 10/12/91, España, CREA)

b. Aspiolea aseguró que lo estratégico en Guáimaro es trabajar en la solución definitiva, a partir de la presa Jobabito, con 19 millones $500000 \mathrm{m3}$ de capacidad, una inversión, precisó, que puede parecer grande, pero factible de determinar rápidamente con el rescate de recursos en la provincia y el apoyo del organismo nacional. (Granma Internacional, 5/1997, Cuba, CREA)

Los grupos nominales en negrita de los ejemplos anteriores refieren anafóricamente a los previamente subrayados: en (1a) se repite el sustantivo comunidades y en (1b) se utiliza el nombre inversión como una anáfora asociativa relacionada con la presa Jobabito, basada en el conocimiento compartido por los hablantes de que la construcción de toda obra civil requiere una inversión monetaria. En ambos casos, el grupo nominal anafórico es indefinido y está modificado por una oración de relativo restrictiva, encabezada por el relativo que. También en ambos casos el grupo nominal anafórico se interpreta como el tópico sobre el que la oración de relativo aporta una información novedosa.

El análisis de este tipo de estrategia topicalizadora tiene interés para el conocimiento de la interfaz sintaxis-pragmática por varias razones.

En primer lugar, la estrategia se fundamenta en la posibilidad de usar anafóricamente el determinante indefinido, lo que contradice la idea

Cristina Sánchez López, Universidad Complutense de Madrid, Madrid, España 
generalmente aceptada de que los indefinidos, al contrario que los definidos, introducen nuevas entidades en el dominio del discurso y no entran en relaciones anafóricas (Karttunen 1976, Kamp 1981, Heim 1982, Leonetti 1999, 2007, Sánchez López 1999, entre otros). Datos como los de (1) desafían, por consiguiente, la definición de indefinitud y reclaman un análisis que explique, por una parte, cómo son posibles estos usos, y, por otra, hasta qué punto la codificación de la función de tópico mediante ciertas estructuras gramaticales puede tener consecuencias a nivel sintáctico-semántico.

Además, en ella se utilizan las subordinadas de relativo como parte de una estrategia al servicio de la estructura informativa. La oración de relativo contiene información novedosa, y puede considerase foco informativo; al mismo tiempo, hace que el sustantivo al que modifica sea interpretado necesariamente como un tópico que recupera información ya introducida en el discurso. Datos como los de (1) amplían, pues, el repertorio de valores discursivo-informativos de las oraciones de relativo, relacionados generalmente con las cláusulas hendidas y pseudohendidas. ${ }^{1} \mathrm{Su}$ análisis debería desentrañar cuál es exactamente la contribución de la cláusula de relativo a la construcción.

Este estudio se ilustra con ejemplos tomados de las bases de datos Corpus del Español Actual (en adelante CREA) y Corpus del Español del Siglo XXI (en adelante CORPES), ambos de la Real Academia Española. A juzgar por los datos recopilados, y a falta de un estudio dialectal exhaustivo, se puede afirmar que no existen diferencias geolectales notables en cuanto a la aceptación y uso de la construcción, que se documenta en todas las variedades del español. Sí parece haber, en cambio, una notable predilección por la construcción en ciertos géneros discursivos: es más frecuente en el discurso oral planificado que en la conversación informal espontánea; es también más frecuente en los textos periodísticos que en los literarios, y se usa mucho en cierto tipo de discurso político. Los ejemplos estudiados ilustran estas tendencias, pero no es mi objetivo proporcionar datos cuantitativos que las demuestren. Mi interés principal es explicar los mecanismos gramaticales y semánticos que subyacen a la construcción, pues es en ellos donde sintaxis y discurso interactúan.

El trabajo se organiza como sigue: en la sección 2 se describirá la construcción a partir de datos reales tomados de los corpora CREA y CORPES; en la sección 3 se analizará la aportación de la cláusula subordinada de relativo al uso anafórico del indefinido y el rendimiento discursivo de esta estrategia por oposición a otros mecanismos de marcado de los tópicos. El trabajo terminará con la enumeración de algunas conclusiones.

1 Véase, por ejemplo, Moreno Cabrera (1999) y De Cesare (2014). El uso de los relativos como marcadores del discurso se analiza en Pascual y Romero (2016). 


\section{Descripción de la construcción: anáforas indefinidas (y por qué no deberían serlo)}

Las expresiones referenciales pueden establecer relaciones de correferencia que garantizan la adecuada cohesión del texto en que aparecen. Estas relaciones, denominadas anafóricas, dan lugar a redes correferenciales, cadenas nominales, o anáforas textuales. Desde el punto de vista discursivo o textual, una anáfora es cualquier elemento que establece unívocamente su referencia por correferencia con otra expresión presente en el texto. Según la semántica instruccional (cfr. Conte 1988, 25), una anáfora es una instrucción que le indica al oyente o lector que debe buscar en otro elemento textual (nominal, verbal, adverbial), ya presente en el texto, la información para poder determinar el objeto o la entidad designada. ${ }^{2}$

Las expresiones nominales utilizadas en este tipo de relaciones anafóricas o redes correferenciales son típicamente pronombres o sintagmas nominales definidos, introducidos por el artículo definido, los demostrativos o los posesivos. La propiedad semántica de la definitud es responsable de que tales grupos nominales puedan adquirir usos anafóricos.

La definitud es una propiedad semántica que consiste en la indicación de que el referente del grupo nominal es identificable para el receptor en el contexto de uso. Los grupos nominales definidos inducen la presuposición de que el receptor puede construir una representación mental adecuada del referente e identificarlo de manera unívoca sin ambigüedad (Leonetti 1999, 39; véase también la reflexión pre-teórica sobre el artículo definido de Bello 1847, $\S 267)$. La posibilidad de construir dicha representación mental se basa en dos condiciones compatibles entre sí, aunque no necesariamente simultáneas: la Condición de Unicidad, consistente en que el referente del grupo nominal definido es único, ya lo sea en términos absolutos o por constricciones contextuales, y la Condición de Familiaridad, que determina que el referente ha de ser conocido dentro del contexto - es decir, familiar-. La definitud, por tanto, obliga al receptor a acceder a los supuestos contextuales necesarios para formarse una representación mental unívoca del referente. Cuando esos supuestos contextuales consisten en la mención previa del referente, los

2 Utilizaré el término anáfora como sinónimo de anáfora discursiva o textual, tal como se hace comúnmente en los estudios textuales y discursivos, y no en el sentido restrictivo que la sintaxis formal atribuye al término para denominar la clase de expresiones referenciales que ha de tener su antecedente en un domino local, como los pronombres reflexivos y recíprocos, entre otros elementos (cf. Bosque y Gutiérrez-Rexach 2009). 
grupos nominales definidos adquieren propiedades anafóricas dentro del discurso.

La semántica de los indefinidos, en cambio, no incluye ninguna instrucción de esa naturaleza. Los estudios que adoptan la perspectiva de la semántica dinámica asumen, como yo haré en este estudio, que los indefinidos introducen nuevos referentes en el discurso (Karttunen 1976, Kamp 1981, Heim 1982, entre otros muchos). Según estos estudios, los indefinidos se diferencian de los definidos por no implicar la unicidad del referente y por no requerir su familiaridad. De la propiedad de no familiaridad se sigue que los indefinidos, un entre ellos, no puedan referir a elementos mencionados en el discurso precedente. El contraste que aparece en el siguiente ejemplo ilustra esta restricción:

\section{(2) Un hombre ${ }_{i}$ entró en la habitación; $\{$ el/*un $\}$ hombre $\boldsymbol{~}_{\boldsymbol{i}}$ estaba furioso.}

Si se interpreta que los grupos nominales destacados son correferentes, como piden los subíndices, solo el uso del artículo definido es posible. El uso del indefinido es incompatible con la relación de correferencia entre los dos sintagmas porque produciría una incongruencia: por un lado, el indefinido indica que el referente de la expresión un hombre no es familiar ni único, y en consecuencia, no es accesible para que el oyente construya una representación adecuada de él; por otro, la relación de correferencia obliga a considerar que el referente ya ha sido mencionado previamente y, por tanto, es familiar y accesible para el oyente. En consecuencia, la relación de correferencia en (2) convierte la secuencia en un enunciado no interpretable. ${ }^{3}$

Si la incapacidad de los indefinidos para establecer relaciones anafóricas en el discurso se ha atribuido unánimemente al hecho de que no puedan tener un referente familiar, los estudios difieren, sin embargo, en considerar si los indefinidos están realmente marcados con los rasgos de no-familiaridad y no-unicidad o bien están infra-especificados para ellos. Avalaría la segunda opción el hecho de que en ciertos contextos alguno de estos requisitos pueda incumplirse, de manera que los indefinidos acomoden su interpretación a contextos de familiaridad. ${ }^{4}$ En esa

3 El uso del indefinido, de hecho, será posible si se interpreta que no existe correferencia entre los dos grupos nominales, esto es, si en la secuencia Un hombre entró en la habitación; un hombre estaba furioso cada sujeto refiere a un individuo diferente.

4 Es el caso de los "indefinidos partitivos", que tienen interpretación específica y requieren un dominio definido y familiar que restrinja sus posibles valores (cf. Enç 1991, Farkas 2002). Este dominio puede estar explícito en forma de coda partitiva o bien estar implícito, como se muestra en (i):

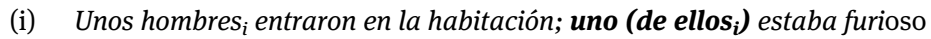


dirección me gustaría avanzar para explicar los casos del español que nos interesan.

Contrariamente a lo esperado, los grupos nominales indefinidos refieren a entidades previamente mencionadas en el discurso en los ejemplos que nos ocupan. Las maneras en que estos indefinidos anafóricos se introducen en el discurso son diversas. En el caso más sencillo, el indefinido repite el sustantivo que le sirve como antecedente. Puede no haber distancia entre ellos, como en los ejemplos de (3), donde el indefinido parece funcionar como una aposición al antecedente; la inmediatez entre ambos permite pensar que en casos como (3a) podría haberse evitado la repetición del sustantivo:

(3) a. Hace reír, con intención y con fortuna, la suerte de aquella alma: un alma que sufre porque sin cuerpo no puede enderezar las torceduras que en su presunta ausencia puede percibir. (J. J. Reyes, "Penas de un fantasma provinciano”, Letras Libres, 1/2005, México, CORPES)

b. El cuaderno de notas que resultaba de esto no es fácil de superar, pero sí ayuda a recalcar la locura necesaria para luchar por esa ventura infantil en todo lo que tiene de absurdo, de un absurdo que el exilio sólo acentúa. (N. Manea, "El lenguaje como patria”, Letras Libres, 4/2005, México, CORPES)

En otras ocasiones, el indefinido sigue inmediatamente al grupo nominal que contiene al antecedente, pero está separado de éste por uno o varios complementos. El indefinido anafórico repite el sustantivo, pero no sus modificadores:

(4) a. Leímos el cuento "María Soledad" de Chabela Lora. Un cuento que no es infantil, pero también arroja cómo se puede hacer una literatura diferente para los adultos y adultas. (A. Segura, "Un reporte de trabajo sobre los cuentos que 'nos contaron'”, A Primera Plana, 6/2005, República Dominicana, CORPES)

Los indefinidos partitivos, a diferencia de los estudiados aquí, no mantienen relación de correferencia con un potencial antecedente ya que es la coda partitiva (en concreto, el pronombre ellos) quien lo hace.

También incumplen la condición de no familiaridad los "indefinidos no novedosos" (cf. la nota 12, más adelante), que estudia Krifka (2001). Finalmente, los llamados "indefinidos dependientes" (dependent indefinites, cf. Farkas 1997, Brasoveanu y Farkas 2016) no establecen relaciones anafóricas de correferencia sino relaciones cuantitativas de co-variación con otro cuantificador, y no son, por tanto, un caso relevante para el fenómeno que nos ocupa. 
b. Hoy estamos aquí con el único propósito de contribuir a garantizar el próximo triunfo del Partido Nacional de Honduras. Un triunfo que en esta fiesta nacionalista se inicia a construir a través de la unidad total del nacionalismo. ("M. Pastor: Seré un soldado más para que 'Pepe’ sea presidente”, La Tribuna, 15/05/2005, Honduras, CORPES)

Finalmente, el indefinido anafórico puede repetir el sustantivo que aparece en su antecedente, pero la distancia sintáctica que media entre ambos es tal que no podría considerarse que aquel sea una aposición a éste. En el ejemplo siguiente, nótese que el pueblo morelense forma parte del complemento del nombre lucha, esto es, ocupa una posición incrustada dentro de otro grupo nominal, de modo que una relación de aposición con el indefinido anafórico sería imposible $e^{5}$ :

(5) Durante los últimos días hemos sido testigos a través de diversos medios de comunicación de la lucha del pueblo morelense por defender su dignidad y libertad. Un pueblo que se niega a seguir siendo rehén de la delincuencia y de la impunidad, pero, también, de la resistencia a ultranza de un gobierno que ha perdido legitimidad y que ha recurrido a las acciones más bajas para preservarse en el poder. (Oral, Sesión pública ordinaria de la Honorable Cámara de Senadores, 2/04/1998, México, CREA)

5 Las aposiciones introducen una predicación secundaria de carácter nominal usada para especificar o explicar otra palabra de la misma especie (Suñer 1999, 525). Se requiere adyacencia y, generalmente, equivalencia funcional, entre la aposición y la palabra a la que se aplica, que se unen por yuxtaposición. Algunos ejemplos analizados aquí cumplen estas condiciones. En otros, en cambio, es imposible considerar que se produzca aposición por la configuración sintáctica de la secuencia. En el caso de (5) el sintagma el pueblo morelense podría ser modificado por una aposición adyacente, como se ilustra en (ia), pero su posición incrustada impediría que fuese modificado por una aposición situada en el lugar de la estructura topicalizadora, como se muestra en (ib). Esto sugiere que la sintaxis de la construcción que nos ocupa no puede reducirse a su mera consideración como aposición, salvo que esta se considerase a nivel textual, idea con la que nuestro análisis no sería incompatible:

(i) a. Durante los últimos días hemos sido testigos a través de diversos medios de comunicación de la lucha del pueblo morelense, un pueblo ejemplar, por defender su dignidad y libertad.

b. ??^Durante los últimos días hemos sido testigos a través de diversos medios de comunicación de la lucha del pueblo morelense por defender su dignidad y libertad, un pueblo ejemplar. 
Si en los ejemplos anteriores el indefinido anafórico repetía el sustantivo de su antecedente, en los que vienen a continuación se utiliza un nombre distinto y el indefinido vuelve a nombrar el referente con algún otro sustantivo. Este puede ser un hiperónimo, como en (6), donde se utilizan hombre y mujer para referir al antecedente, ya sea este un nombre común, como en (6a) o un nombre propio, como en $(6 \mathrm{~b}, \mathrm{c})$ :

(6) a. El movimiento artístico de Aragua y el país queda resentido con la partida de nuestro amigo, un hombre que entre los avatares de la poesía escondió su cuerpo para intentar continuar viviendo. Su escritura no descansaba. Su pintura fue alojo de solidaridad y afecto por sus fantasmas, fijaciones y constantes. (A. Hernández, "Aly Pérez: una barca entre la niebla”, Letralia, 7/02/2005, Venezuela, CORPES)

b. Este filme de Víctor Erice está basado en la historia de Adelaida García Morales, una mujer que guardó en su diario los relatos de una niñez y adolescencia vividas durante la transición en la historia española. (“'El Sur’ abrió el festival de cine de Cuenca”, El Comercio, 15/05/2005, Ecuador, CORPES)

c. Es un lujo tener la música en directo de Salif Keita con nosotros esta noche. Un hombre que está a punto de grabar un long-play con la colaboración de músicos tan importantes como Carlos Santana, Wayne Shorter, o Miles Davis y producido por Joe Sabinul. (Oral, Un día es un día, 20/09/90, TVE 1, España, CREA)

Existe también relación de hiperonimia entre anáfora y antecedente en los ejemplos de (7), donde volumen refiere al título de un libro y se incluye cervitis bajo el hiperónimo problema; obsérvese cómo el hiperónimo lenguaje remite a la coordinación de varios hipónimos en (7c):

(7) a. A la publicación de su novela Un siglo tras de mí, el escritor Eloy Urroz sumó recientemente la publicación de Siete ensayos capitales (Taurus), un volumen que reúne textos sobre autores latinoamericanos que ha leído con particular devoción. (J.L. Espinosa, "Analiza Eloy Urroz a sus autores capitales de AL”, El Universal, 3/01/2005, México, CORPES)

b. Pero estas sustancias también pueden ocasionar alergias en algunas mujeres. Una de las reacciones más habituales es la cervicitis o inflamación del cuello uterino, un problema que afecta a más de la mitad de las mujeres en algún momento de su vida adulta, y que la mayoría de 
las veces se debe a una infección. (R. Gaia, "Alergias íntimas”, La Guía, 8/2005, Estados Unidos, CORPES)

c. Adscrito al nadaísmo, el cual aborrecería luego, Cataño publicó en 1966, en lujosa edición, un cuaderno con sus escritos al cual tituló Poemas urbanos, con una prosodia, sintaxis y vocabulario extraídos de sí mismo y que pretendía representar el mundo citadino de entonces. Un lenguaje que, por lo ordinario y banal, pretendidamente proletario (¿cuál será el lenguaje de los proletarios?), es la antítesis de cualquier poema. (H. Alvarado Tenorio, “Mario Rivero”, Letralia, 7/03/2005, Venezuela, CORPES)

La relación léxica existente entre el antecedente y el indefinido anafórico puede acercarse a la sinonimia. El sintagma nominal anafórico realiza entonces una suerte de reformulación o redefinición del antecedente, como en este ejemplo:

(8) ...Parker convirtió el jazz en otra música de la que encontró cuando empezó a espiarlo a Lester Young en Kansas City. Entre el swing y el be-bop no hay evolución sino ruptura, un salto que los conservadores de siempre -el sordo Ives Panassié desde la teoría- o los revolucionarios históricos incluido el glorioso Armstrong, desde el podio- consideraron al vacío. (J. Sasturain, “¿Cuánto estás dispuesto a pagar por saxo?”, Página/12, 27/ 02/2005, Argentina, CORPES)

Los hiperónimos utilizados anafóricamente han sido incluidos dentro de la categoría discursiva de encapsuladores anafóricos (D’Addio Colosimo 1988, 144) o anáforas conceptuales (Moirand 1975, 65ss.), esto es, grupos nominales de naturaleza inclusiva o sintetizadora que refieren de forma concisa a algo mencionado previamente. Estos elementos realizan una doble función: por una parte, remiten a expresiones previamente introducidas, por lo que estrictamente hablando no añaden nuevos referentes al discurso; por otra parte, no son informativamente neutros pues sirven de enlace entre dos bloques textuales, sintetizando el primero y sirviendo de punto de partida del segundo. Halliday y Hasan (1976, 274) atribuían la función de encapsulador a un pequeño conjunto de nombres de referencia muy general (ser humano, persona, lugar, espacio, hecho, estado, acontecimiento, etc.), esto es, los llamados "nombres generales" (cf. los ejemplos de (6) y (7)). La mayoría de los autores reconoce hoy esta función también a las nominalizaciones que engloban uno o varios predicados verbales, como puede verse en los trabajos de D'Addio Colosimo (1988), Conte (1996), Borreguero (2006), González Ruiz (2010), Llamas 
Sáiz (2010), Pecorari (2014), entre otros. Todos los estudios sobre encapsuladores coindicen en limitar esta función textual a los grupos nominales definidos.

Como queda dicho, también los grupos nominales indefinidos de la construcción que nos ocupa pueden manifestar este uso. Se describen a continuación algunos de los casos más representativos.

En primer lugar, los encapsuladores pueden ser sustantivos de significado muy general y escasamente descriptivo, como cuestión, tema, factor, que refieren de forma sintética a la situación largamente descrita en el discurso previo; se trata de sustantivos con escasa carga semántica, una especie de comodines que, de forma bastante neutra, recuperan el contexto previo sin añadir apenas contenido descriptivo. Los ejemplos de (9) ilustran este caso:

(9) a. Ello significa que a medida que WAP aumente sus aplicaciones y sus fans, también serán mayores sus vulnerabilidades ante hackers y virus informáticos, una cuestión que en buena medida tendrá que atacarse del lado técnico. (N. Acosta, "Resurge la tecnología WAP”, El Universal, 11/8/2005, México, CORPES)

b. Y es que, si los libros llevaban meses en las escuelas, lo prudente habría sido investigar qué había sucedido en las aulas. Un tema que, vale subrayar, tampoco ha motivado indagación periodística alguna ni parece preocupar a los detractores de la selección de los acervos: les basta con sus prejuicios. (D. Goldin, “¿País de lectores?”. Letras Libres, 4/2005, México, CORPES)

c. "[La internación domiciliaria] también es útil para la implementación de una alta temprana y la continuación de un tratamiento en el hogar del paciente, un factor que determina mejores condiciones para su recuperación por la relación permanente con su núcleo familiar, que respeta sus costumbres y valoriza el afecto", agregó. ("CADEID desarrollará su Primer Congreso”, Médicos, 3/2005, Argentina, CORPES)

Pero es posible también utilizar como encapsuladores nombres más descriptivos que, además de sintetizar, añaden una cierta caracterización semántica informativamente relevante. Así, iniciar una expansión comercial se caracteriza como una estrategia en (10a), limpiar la cara es un rito en (10b), y la máxima reproducida en (10c) es un ideal:

(10) a. Para Jeff Bell, vicepresidente de Jeep, el Commander es significativo por el compromiso que tiene la marca para seguir siendo líder en el mercado de los SUV, y también por su configuración interior de siete asientos. 
Asimismo, por representar una nueva gama de vehículos y porque con él se inicia la expansión de la línea de modelos Jeep; una estrategia que se intensificará en la segunda parte de esta década. ("Desde Nueva York Especial para AutoGuía”, Washington Hispanic, 22/4/2005, Estados Unidos, CORPES)

b. Después del aseo personal y la ducha diaria, mientras el albornoz absorbe la humedad de la piel, destine un par de minutos a limpiar la cara, un rito que jamás se debe olvidar. (C. Martín, "Belleza Express”, La Guía, 2/2005, Estados Unidos, CORPES)

c. Este análisis sugiere de antemano los lineamentos estéticos que habrán de dar forma a la estructura del lenguaje y composición de España contemporánea, que sin lugar a dudas emana del postulado martiano que enuncia: "El verso se improvisa, pero la prosa no; la prosa viene con los años” (Ghiano, 30). Un ideal que Martí ya había previsto durante su juventud. (J.C. Hernández Cuevas, "De Nueva York a España: visiones finiseculares de dos mundos”, Letralia, 7/3/2005, Venezuela, CORPES)

El último ejemplo ilustra una relación sintáctica y discursiva remarcable entre anáfora y antecedente, pues cada uno de ellos procede de un participante distinto en el discurso. La cita entrecomillada es discurso reproducido atribuible al autor que aparece entre paréntesis; la anáfora que la encapsula (un ideal que Martí ya había previsto durante su juventud) forma parte del discurso atribuible al autor del texto. Se encuentra una disociación parecida en el ejemplo de (11), aunque en este caso es la anáfora la que pertenece al discurso reproducido:

(11) Hoy el nacionalismo le está brindando a Honduras una gran contribución y eso es un Partido Nacional unificado con el cual se van a decidir objetivos fundamentales para seguir esa ruta de desarrollo y de transformación que urgentemente necesita Honduras. "Una ruta que junto a Porfirio Lobo y el nacionalismo hondureño la vamos a construir, una ruta que le dará a cada hondureño mejor calidad de vida", apuntó el edil capitalino. ("Miguel Pastor: Seré un soldado más para que 'Pepe' sea presidente”, La Tribuna, 15/5/2005, Honduras, CORPES)

Los ejemplos de (10) y (11) demuestran que puede existir entre anáfora y antecedente un salto no solo sintáctico, pues pertenecen a oraciones distintas, sino también discursivo, pues corresponden a distintas voces. La ruptura puede apreciarse incluso en condiciones de gran proximidad. En el ejemplo 
que se reproduce a continuación, antecedente y anáfora se suceden inmediatamente, pero pertenecen a actos de habla diferentes: aquel se encuentra dentro de una pregunta, retórica ciertamente, y esta encabeza una oración enunciativa que aporta el argumento que justifica la presuposición escondida en la interrogación retórica; ambos enunciados parecen, pues, corresponder no solo a oraciones independientes, sino también a niveles discursivos distintos:

(12) ¿Por qué confiar más en el laboratorio desorganizado e indiscreto del país sede? Una sede que esperaba desplazar a Cuba del segundo lugar que ocupábamos ya de forma definitiva e irremplazable, sin olvidar que con la medalla ganada por él, sumada a las de otros diez héroes de aquella proeza, desplazamos a Estados Unidos del primer lugar en uno de sus deportes más fuertes. Al arrebatarnos la medalla de Sotomayor, nos despojaron también de ese honor. (Oral, Comparecencia de Fidel Castro en el Programa Especial sobre el Movimiento Deportivo Nacional, Cuba, CREA)

La anáfora puede, a veces, remitir simultáneamente a varios antecedentes. El texto reproducido en (13a) menciona en tres ocasiones el sustantivo futuro: las dos primeras dentro de un sintagma nominal definido; la tercera dentro de un sintagma nominal indefinido que remite a los dos anteriores y los caracteriza a un tiempo. El texto recogido en (13b), por su parte, contiene la anáfora discursiva una lección, que reúne y caracteriza las dos situaciones descritas por sendas oraciones previas:

(13) a. Pero volviendo al tema que motivó estos comentarios, es justo destacar que el príncipe Carlos, en un acto posterior al mencionado, se permitió decir que el futuro de la monarquía en Australia dependía de los australianos $y$ de sus procedimientos democráticos. Y no ha faltado quien leyera en sus palabras un cierto paralelismo con su propio futuro en Inglaterra. Un futuro que, de momento, se presenta lleno de interrogantes. ("En torno a un viaje", La Vanguardia, 13/02/1994, España, CREA).

b. Primera clave: este equipo no almacena la información personal en su memoria, sino en un espacio provisto por el operador. Segunda clave: Paris, al igual que millones de personas, apenas le da importancia a las contraseñas que resguardan sus secretos. Una lección que los usuarios de celulares deberán incorporar muy pronto... (R. Bini, “Celulares inteligentes, pero vulnerables", La Nación, 7/3/2005, Argentina, CORPES). 
Los ejemplos reproducidos en (11), (12) y (13) se caracterizan por la distancia sintáctica, y en ocasiones discursiva, que media entre anáfora y antecedente. Como queda dicho, esta distancia hace imposible considerar que la anáfora pueda ser analizada como una suerte de aposición de su antecedente, ya que la construcción topicalizadora exhibe un comportamiento sintáctico autónomo. $\mathrm{Su}$ independencia sintáctica es evidente en textos escritos, como (14a), pero alcanza su mayor expresión en el discurso oral, como el de (14b), donde un locutor utiliza la construcción anafórica para retomar un tópico que había abandonado tiempo atrás:

(14) a. ...es comprobar con asombro renovado la infinita energía humana e intelectual de Ezra Pound, su reserva casi animal de vigor y alerta -él mismo habiéndose definido con su franqueza habitual como un "paquidermo" insaciable. Una energía que, vista en retrospectiva y desde estas páginas vastas, parece hija del genio de Pound, del genio de una época (la de la primera mitad del siglo XX, cuando florece el movimiento poético moderno... (D. Torres Fierro, "Poems \& Translations, de Ezra Pound”. Letras Libres, 6/2005, México, CORPES).

b. ... el Consejo Superior de Deportes ha concedido el premio a la Federación española de Fútbol por su campaña “juego limpio”. Es bueno [sic] la competitividad, es bueno [sic] la lucha, la brega el intento de conseguir la victoria, pero siempre dentro de la deportividad. Una campaña que yo no sé si está dando los frutos que se esperaban de ella, y. . pero creo que el personaje que está con Juan Carlos Ribero nos lo puede aclarar. Adelante, Juan Carlos. (Oral, Televisión, 5/7/91, España, CREA)

Para completar la descripción, es preciso mostrar que el indefinido anafórico puede ser un grupo nominal indeterminado. Ilustran esta posibilidad los ejemplos de (15) y (16). En los primeros, el indeterminado anafórico repite su antecedente. En los segundos, la anáfora es un encapsulador que resume y caracteriza un enunciado oracional previo; este puede ser un único enunciado, como en (16a), o una situación compleja descrita por varias oraciones, como en (16b):

(15) a. El acuerdo de paz con las FARC, crea de todos modos un hecho con los grupos guerrilleros. Hecho que jamás era de sumisión al acuerdo de La Uribe, sino de tomar posiciones sobre si estaban dispuestos a continuar el diálogo. (A. Alape, La paz, la violencia: testigos de excepción, Colombia, CREA).

b. La Fortuna quiso recompensar a los humanos deparándoles momentos como éste. Cuando sólo el deseo llena los espacios que separan a los 
cuerpos. Deseo que no compromete. Deseo que une y no esclaviza. ¡Ojalá puedan dártelo mil mujeres cuando hayas olvidado a esa loca de los rojos cabellos! (T. Moix, No digas que fue un sueño, España, CREA)

(16) a. Escucharon la primera canción, Amaro asintió y le pidió escuchar la segunda. Terminó ésta y propuso oír la tercera. A la mitad, se levantó del escritorio y pronunció la frase que cambió la historia del grupo: "en agosto firmamos". Promesa que cumplió en la fecha prevista. ("La suerte escondida de una secta rockera”, El Nacional, 1/9/1997, Venezuela, CREA).

b. Al respecto, cabe destacar que tales avances sucedieron en una etapa de la vida nacional en la cual la estrechez financiera y las perturbaciones del país fueron más intensas; además, en ella se comprometieron muchas más regiones y grupos sociales que en los no poco agitados decenios anteriores de vida independiente. Situación que se agravó más aún a partir de la guerra de 1847. (S. de la Peña, Visión global de los orígenes de la estadística, México, CREA)

Con todo, la ausencia de determinante en el grupo nominal anafórico es más rara e infrecuente que el uso del indefinido un. Merece la pena destacar que ningún otro determinante puede ser utilizado para esta función, excepto el indefinido de contraste otro cuando tiene sentido aditivo, esto es, cuando significa 'uno más'. ${ }^{6}$ Este es el sentido que tiene en los muy escasos ejemplos que he documentado en las fuentes consultadas, de los que (17a) es una muestra; nótese que el sintagma otro momento tiene en este ejemplo un sentido similar al que tiene un francés más en (17b), que podría alternar con otro francés:

(17) a. Frenó a los impacientes, e incluso "echó presos a dos hombres de los que vinieron con aquellas pláticas y los trató mal y estuvo por les ahorcar". Ese fue quizás el momento más propicio para cortar nexos con España. Otro momento que dejó pasar. (J. Miralles, Hernán Cortés. Inventor de México, México, CREA).

b. ...el ministro de Cultura francés (...), que se encuentra también para estar presente en este día de hoy, junto a Laurent Jalabert, el francés que ha conseguido. .. que va a conseguir dentro de un rato, de forma definitiva

6 Véase Eguren y Sánchez López (2003, 2004) a propósito de este indefinido y sus distintos valores semánticos. 
ya, el triunfo en esta cincuenta edición de la Vuelta ciclista a España. Un francés más que unir a la lista de ganadores de la carrera que son bastantes desde los inicios de la prueba española. (Oral, Vuelta ciclista a España, 24/9/95, TVE 1, España, CREA).

Cuando otro tiene sentido de contraste, esto es, cuando significa 'un N diferente', no puede ser anafórico, ya que ese sentido exige justamente considerar que el sintagma nominal refiere a una entidad distinta de alguna otra que haya sido mencionada previamente. Sin embargo, en ese caso el sintagma puede tener valor catafórico y ligarse a una expresión que aparecerá posteriormente. Así sucede en el ejemplo (18), donde otro punto que ... contiene el encapsulador punto y remite catafóricamente al contenido discursivo que sigue:

(18) Pero nuestra postura, y los Diarios de Debates de Cámara de Diputados lo dejaron claro, era la facultad ordinaria (...). Otro punto que quiero destacar a ustedes. Hay dos palabras: una, incorporada, por cierto, por Cámara de Senadores, que aluden al vínculo entre Cámara de Diputados y el Órgano Superior de Fiscalización, son las palabras coordinar y evaluar. (Oral, Sesión pública ordinaria de la Honorable Cámara de Senadores, celebrada el martes 27 de abril de 1999, México, CREA).

En resumen, los grupos nominales indefinidos - generalmente introducidos por un/a/os/as, y ocasionalmente indeterminados o introducidos por otro(s) - modificados por una oración de relativo restrictiva pueden funcionar como anáforas discursivas. Este comportamiento contradice la caracterización general de los indefinidos como elementos que introducen nuevos referentes en el discurso, y pone en cuestión las explicaciones sintácticas que circunscriben la capacidad anafórica a los sintagmas nominales definidos negándosela a los indefinidos.

Pese a su indefinitud, estos indefinidos se comportan como anáforas discursivas en todos los aspectos: pueden repetir el sustantivo de su antecedente o bien establecer con él una relación de anáfora conceptual por medio de hiperónimos o encapsuladores; pueden remitir a expresiones referenciales o bien resumir situaciones expresadas por secuencias oracionales; pueden seguir inmediatamente a sus antecedentes o estar separados de ellos. En todos los casos, el indefinido anafórico es un grupo nominal con una estructura bimembre: el sustantivo precedido por el indefinido se comporta discursivamente como un tópico sobre el que la oración de relativo aporta información focal novedosa.

En el apartado siguiente propondré un análisis que profundiza, precisamente, en el papel que juega la oración de relativo como portadora de la información nueva y que explicaría por qué la construcción ha podido llegar a convertirse en un procedimiento para marcar el tópico. 


\section{El papel de la oración de relativo y la naturaleza nominal de la construcción topicalizadora}

Además de usar un indefinido para introducir un elemento previamente mencionado en el discurso, dos rasgos sintácticos caracterizan la construcción objeto de este estudio: uno es la obligatoriedad de la oración de relativo, el otro es la naturaleza no oracional de la construcción completa. Un análisis que intente explicar por qué los indefinidos pueden constituir anáforas discursivas habrá de explicar al mismo tiempo cuál es el papel que ambas propiedades tienen en la legitimación de la construcción como estrategia de topicalización. A ello se dedica este apartado.

La oración de relativo restrictiva es, en efecto, obligatoria. Sin ella, el indefinido no podría referir anafóricamente al grupo nominal previo. Prueba de ello es que la construcción resultaría inaceptable si no mediase el relativo entre el indefinido y el predicado, como se intenta mostrar con los ejemplos de (19), que adaptan ejemplos reales presentados en la sección anterior ${ }^{7}$ :

(19) a. Es un lujo tener la música en directo de Salif Keita con nosotros esta noche. Un hombre *(que) está a punto de grabar un long-play.

b. Hemos sido testigos de la lucha del pueblo morelense por defender su dignidad y libertad. Un pueblo *(que) se niega a seguir siendo rehén de la delincuencia.

c. A medida que WAP aumente sus aplicaciones y sus fans, serán mayores sus vulnerabilidades ante hackers y virus informáticos. Una cuestión *(que) en buena medida tendrá que atacarse del lado técnico.

Una prueba adicional de la relación entre el uso anafórico del indefinido y la obligatoriedad de la cláusula de relativo se obtiene al cambiar el indefinido por un determinante definido (ya sea un demostrativo, ya sea el participio dicho recategorizado como determinante, ya sea el artículo definido); en tal caso el grupo nominal definido no podría estar modificado por la oración de

7 (19a) adapta el ejemplo (6c), (19b) adapta el ejemplo (5) y (19c) adapta el ejemplo (9a). Se ha omitido el contexto no pertinente y se ha modificado únicamente aquello que demuestra la existencia de una pauta sintáctica relevante. 
relativo, sino que se integraría como sujeto del verbo antes subordinado $\mathrm{y}$ ahora principal:

(20) a. Es un lujo tener la música en directo de Salif Keita con nosotros esta noche. Este hombre ( ${ }^{*}$ que) está a punto de grabar un long-play.

b. Hemos sido testigos de la lucha del pueblo morelense por defender su dignidad y libertad. Dicho pueblo ( ${ }^{*}$ que) se niega a seguir siendo rehén de la delincuencia.

c. A medida que WAP aumente sus aplicaciones y sus fans, serán mayores sus vulnerabilidades ante hackers y virus informáticos. La cuestión ( ${ }^{*}$ ue) en buena medida tendrá que atacarse del lado técnico.

La interdependencia entre el posible uso anafórico de un indefinido y la presencia de una oración de relativo restrictiva fue observada por Leonetti $(2007,29)$, quien lo ilustra con este ejemplo:

(21) La Universidad de Alcalá resurgió a mediados de los años 70. En poco tiempo, una institución que había vivido momentos de esplendor en el siglo XVI recuperó gran parte de sus edificios históricos.

La relación anafórica del grupo nominal indefinido (una institución que había vivido momentos de esplendor en el siglo XVI) y su antecedente (La Universidad de Alcalá) es explicada por Leonetti como el resultado de un proceso de "reclasificación” o "nueva descripción” de una entidad ya mencionada. La presencia de ciertos rasgos que se presentan como informativamente relevantes, aportados por la oración de relativo, permitirían volver a describir una entidad sin, aparentemente, incumplir el requisito de no familiaridad de los indefinidos.

Siendo esto cierto, no lo es menos que en el ejemplo anterior existe de hecho una relación anafórica del indefinido, lo que no sería esperable, y que se elige deliberadamente un indefinido que debería estar proscrito en lugar de un posible artículo definido (cf. ... la/esta/dicha institución que había vivido ...). Ambos hechos invitan, a mi parecer, a profundizar en el análisis de la cuestión. La relación entre la estructura informativa de la secuencia y su forma sintáctica puede ser un punto de anclaje adecuado para abordar dicho análisis.

Como queda dicho, sería esperable que un grupo nominal anafórico estuviese introducido por un determinante definido. En el contexto de (21), sería posible una secuencia como Esta institución que vivió momentos de esplendor recuperó sus edificios históricos, en la que el tópico definido esta institución sería unívoco, familiar y correferente con la frase previa La Universidad de Alcalá. La oración de relativo se interpretaría entonces como explicativa, no como 
restrictiva. Como es sabido, las oraciones de relativo restrictivas o especificativas aportan rasgos intensionales al antecedente y restringen su extensión. Resultaría anómalo añadir una restricción intensional a un sustantivo cuya referencia ha quedado establecida discursivamente por correferencia con un antecedente. ${ }^{8}$

Las oraciones de relativo explicativas, también llamadas apositivas, incidentales y suplementarias, son adjuntos que no restringen la denotación del grupo nominal al que modifican (Brucart 2016, 276). Comparten con los incisos su naturaleza parentética o apositiva y una autonomía prosódica que les permite formar grupo entonativo propio. Poseen, además, un estatuto informativo específico: suelen asociarse con información relevante, pero incidental, que se añade de forma potestativa a la información principal. Que los parentéticos aporten información incidental no significa que sean prescindibles en sentido estricto, ya que, de acuerdo con Blakemore (2011), ${ }^{9}$ contribuyen al enriquecimiento pragmático del enunciado que los alberga. Con todo, la subordinada explicativa no podría ser considerada el foco informativo de la secuencia, papel que correspondería al predicado de la oración matriz (recuperó sus edificios históricos).

El uso del determinante indefinido en (21), por el contrario, favorece que la oración de relativo sea interpretada como restrictiva. La relativa restrictiva restringe la extensión del nombre al que modifica, es imprescindible para establecer la denotación del grupo nominal y, en consecuencia, aporta información prominente o focal. A ello se añade que los nuevos rasgos expresados en la oración de relativo son imprescindibles para, como dice Leonetti, volver a describir la entidad. El resultado es que la información contenida en la oración de relativo restrictiva se interpretará dentro del foco informativo de la oración.

Así pues, las dos posibles formas de construir un grupo nominal anafórico seguido de una oración de relativo, a saber, con determinante definido y relativa explicativa o bien con determinante indefinido y relativa restrictiva, no solo difieren sintácticamente sino también informativamente. Como puede verse en (22), sólo la segunda permite la inclusión de la información contenida en la oración de relativo dentro del foco informativo de la oración, junto con el predicado de la oración matriz. Según esto, el uso del anafórico del indefinido en (21) no solo sería posible por las razones aducidas, sino también necesario para atribuir a la oración de relativo interpretación focal.

8 Brucart (1999, 411, n. 18) cuestiona la naturaleza redundante de las oraciones de relativo especificativas cuyo antecedente contiene un demostrativo, y concluye que no son necesariamente explicativas. Creemos que sus argumentos no invalidan los presentados aquí debido a la distinta naturaleza de los demostrativos en uno y otro caso, pues tienen carácter ostensivo en sus ejemplos pero anafórico en el descrito aquí.

9 Véase también Burton-Roberts (2005) y las referencias allí citadas. 
(22) a. esta institución que vivió momentos de esplendor TÓPICO INFORMACIÓN INCIDENTAL

recuperó sus edificios históricos

FOCO INFORMATIVO

b. una institución que vivió momentos de esplendor recuperó sus edificios históricos

TÓPICO FOCO INFORMATIVO

Volvamos ahora a los ejemplos objeto de este estudio. A diferencia de los ejemplos de (21) y (22), la construcción topicalizadora se caracteriza de forma esencial por crear secuencias nominales, que se construyen como un enunciado autónomo, no oracional sino nominal. En la mayor parte de los ejemplos (1) a (18), el grupo $<u n+\mathrm{N}+$ oración de relativo > aparece entre puntos, como una oración independiente, a pesar de que no es tal oración sino un grupo nominal. Esto crea una cierta anomalía sintáctica, pues se presenta como enunciado autónomo una secuencia que no es oracional, pero tiene la ventaja de ser informativamente transparente. La secuencia tiene, desde el punto de vista informativo, una estructura categórica bimembre constituida por un tópico y un foco informativo. En (23) se esquematiza tal estructura:

(23) Es un lujo tener la música de Salif Keita ${ }_{i}$ con nosotros esta noche.

Un hombre ${ }_{i}$ que está a punto de grabar un long-play.

TÓPICO FOCO INFORMATIVO

La construcción topicalizadora prescinde de cualquier predicado matriz y eleva la información contenida en la subordinada de relativo a foco informativo de la secuencia. Resulta así que la posibilidad de utilizar un indefinido seguido de una oración de relativo restrictiva para 'renombrar' una entidad ya presentada - descrita a propósito de (21) y esquematizada en (22b) - , es aprovechada para crear una estrategia que marca la anáfora discursiva indefinida como tópico y la oración de relativo restrictiva como foco informativo.

El reconocimiento de esta estructura informativa bimembre explicaría que, cuando se añaden varias informaciones sobre el mismo tópico, se prefiera sistemáticamente la repetición del relativo que delante de cada una de ellas, tal como sucede en el ejemplo siguiente:

(24) .. .la voluntad de insertarse en una categoría propia, inclasificable, será una marca poderosa y recurrente dispuesta sobre todo a deshacerse de los 
remanentes de cualquier forma de convencionalismo y a desplegar una estrategia literaria singular. Una estrategia que, por ejemplo, pulveriza el registro documental, que no secuestra desde una perspectiva artera al lector sino que lo sitúa ante un hecho del lenguaje que se construye ante sus ojos, que cruza constantemente las fronteras entre... ("Carga de infantería”, Letras Libres, 4/2005, México, CORPES)

El tópico destacado por la estrategia que aquí analizamos tiene propiedades de un tema o tópico dislocado. A diferencia de los tópicos colgantes, ${ }^{10}$ los temas dislocados no introducen un tópico nuevo en el discurso ni modifican el tópico anterior sino que hacen más prominente una entidad temática dada o presupuesta. Esto explica que los tópicos desplazados puedan, al contrario que los tópicos colgantes, repetir un tópico previamente mencionado. La estrategia topicalizadora que aquí se analiza se caracteriza precisamente por repetir un tópico mencionado previamente y por convertirlo en el centro discursivo sobre el que recae la información novedosa que le sigue.

Un aspecto central reclama, todavía, profundizar en el análisis: la naturaleza nominal de la construcción. Como queda dicho, la estrategia topicalizadora tiene como resultado un grupo nominal no inserto en una oración matriz. Esto tiene consecuencias que resultan, a mi juicio, esenciales para explicar la construcción.

La primera tiene que ver con el dominio en el que el indefinido encuentra su interpretación, lo cual a su vez está relacionado con el hecho de que pueda recibir interpretación anafórica. Propondré que la naturaleza nominal de la estructura topicalizadora hace que la clausura existencial del indefinido no se produzca en el nivel oracional sino en el nivel discursivo.

10 Los tópicos colgantes, temas vinculantes o relacionantes, como los destacados en (i), introducen un nuevo tópico o modifican el anterior, suelen ir introducidos por un marcador de tópico, se sitúan a la izquierda de la oración y pueden o no ser correferentes con un constituyente oracional. Los tópicos dislocados, como los destacados en (ii), no introducen temas nuevos, se sitúan en la periferia izquierda o derecha de la oración y se relacionan con otro elemento correferente en su propia oración, que puede ser un pronombre átono o nulo, cuyas marcas formales y funcionales repite. Se detallan estas diferencias, así como bibliografía pertinente, en Bosque y Gutiérrez-Rexach (2009, 683-691):

(i) a. En cuanto a las redes sociales, yo no las utilizo jamás.

b. Pepe, todo el mundo sabe que lo han despedido del trabajo.

c. Por lo que respecta a ese problema, puedes contar con mi ayuda.

(ii) a. Las redes sociales yo no las utilizo jamás.

b. Lo han despedido del trabajo, a Pepe.

c. Ese problema podrás resolverlo con mi ayuda. 
Siguiendo el análisis de los indefinidos basado en Heim (1982), consideraré que estos son variables libres carentes de fuerza cuantificacional propia, que deben ser ligadas de una de estas dos maneras: o bien por un operador no selectivo (esto es, un determinante cuantificacional o un adverbio de cuantificación), ${ }^{11}$ o bien por una operación de clausura existencial. La clausura existencial consiste en añadir un cuantificador existencial que ligue las variables en su dominio; dicho cuantificador podrá adjuntarse bien al ámbito nuclear del cuantificador, bien a un nudo textual.

La primera opción consiste en adjuntar un cuantificador existencial al ámbito nuclear del indefinido, y se aplica siempre que ello es posible. Esta operación es responsable de que en la secuencia de (2), repetida a continuación, cada oración permita (y requiera) la introducción de un operador existencial que liga la variable introducida por cada indefinido; la interpretación detallada en (25), solo es compatible con la lectura de los indefinidos como no correferentes:

(2) Un hombre ${ }_{i}$ entró en la habitación; un hombre $\boldsymbol{~}_{\mathbf{j}}$ estaba furioso.

(25) $\exists x$ (hombre(x) \& entró-en-la-habitación (x)); ヨy (hombre(y) \& estabafurioso (y))

En las fórmulas de (25), $\exists$ representa el cuantificador existencial; $x$ e $y$ son las variables introducidas por los respectivos indefinidos; hombre es la predicación restrictiva que expresa el rango de la variable; entró-en-la-habitación $(x)$ y estaba-furioso $(y)$ son proposiciones que contienen la variable y constituyen el ámbito nuclear de los respectivos cuantificadores $\exists \mathrm{x}$ y $\exists \mathrm{y}$.

11 Así sucede cuando los indefinidos caen bajo el ámbito de un cuantificador genérico, como en las llamadas donkey sentences del tipo Si un hombre posee un burro, lo golpea. En mi opinión, también sería el caso de los "indefinidos no novedosos" estudiados por Krifka (2001), esto es, indefinidos que pueden interpretarse como familiares dentro de una oración genérica si reciben el acento focal. Para Krifka, estos indefinidos presuponen la familiaridad del referente pero no su unicidad. La presuposición se acomoda al contexto genérico, en el que el indefinido actúa como un adverbio de cuantificación. Según Krifka, el sujeto indefinido tiene lectura no familiar en (ia) y familiar en (ib):

(i) a. A freshman usually wears a báseballcap.

un novato normalmente lleva una gorra de béisbol

'La mayoría de los novatos llevan normalmente una gorra de béisbol'

b. A fréshman usually wears a baseballcap.

un novato normalmente lleva una gorra de béisbol

'La mayoría de los que llevan una gorra de béisbol son novatos'. 
Esta operación no puede aplicarse, sin embargo, a nuestra estructura topicalizadora porque no es una oración, sino un grupo nominal, y carece de ámbito nuclear. El indefinido introduce un nombre con un modificador restrictivo y tanto el nombre como la oración de relativo pertenecen al restrictor de la variable. En otras palabras, el hecho de que la estructura topicalizadora que analizamos sea un grupo nominal indefinido 'autónomo', no inserto en ninguna estructura oracional, hace que se interprete desde el punto de vista semántico como una variable no ligada.

La segunda opción para proceder a la clausura existencial consiste en adjuntar el cuantificador existencial a un nudo textual, esto es, a un constituyente mayor que la oración formado mediante una operación de creación de texto, esto es, mediante la adjunción de varias oraciones bajo un nudo T (texto) (cf. Heim 1982, 90ss.). En ese caso, el operador existencial podrá ligar varias variables, que se interpretarán como correferentes. ${ }^{12}$ Mi hipótesis es que el cierre existencial de la estructura topicalizadora se produce así: estos grupos nominales sintácticamente autónomos se unen con oraciones del discurso previo para formar una unidad textual y la adjunción de un operador existencial al nudo textual resultante permite que se produzca la clausura existencial del antecedente y del indefinido, que se interpretarán como referencialmente idénticas. El resultado de ambas operaciones (formación de texto y clausura existencial) aplicado al ejemplo de (26) sería como se esquematiza en (26b); la interpretación resultante será la de (26c):

(26) a. Es un lujo tener la música en directo de Salif Keita con nosotros esta noche. Un hombre que está a punto de grabar un long-play. b.

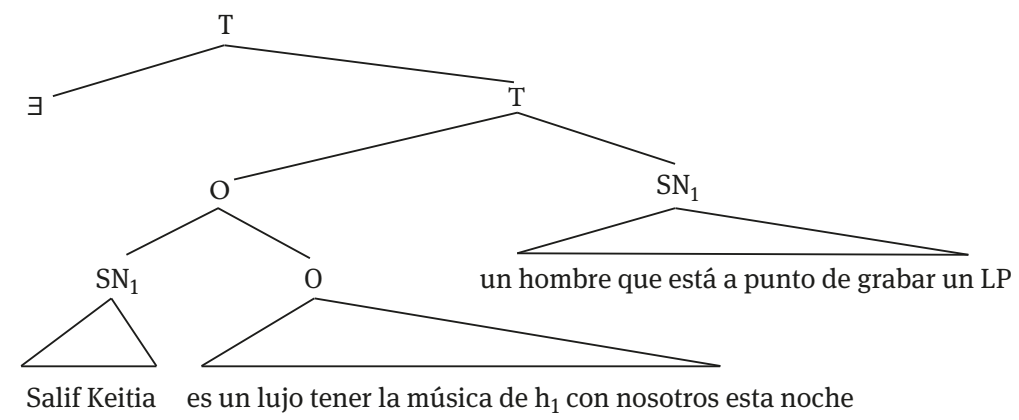

12 Heim $(1982,92)$ propone que la regla de "formación de texto" se aplica a secuencias con varios indefinidos correferentes, como He went to a restaurant $t_{i}$. $t_{i}$ was expensive 'Él fue a un restaurante. Era caro'. 
c. $\exists \mathrm{x}_{1} \quad\left(\left(\right.\right.$ Salif $\operatorname{Keitia}\left(\mathrm{x}_{1}\right) \wedge($ es-un-lujo-tener-con-nosotros-esta-noche-lamúsica-de $\left.\left(\mathrm{x}_{1}\right)\right) \wedge\left(\right.$ un hombre $\left(\mathrm{x}_{1}\right) \wedge$ está-a-punto-de-grabar-un-LP $\left.\left(\mathrm{x}_{1}\right)\right)$

Ello nos lleva a la segunda consecuencia esencial de la naturaleza nominal de la construcción que nos ocupa. Si la legitimación semántica de la estrategia topicalizadora se produce en el nivel discursivo, y no en el meramente oracional, se predice que para interpretar semánticamente el grupo nominal indefinido será obligado considerar unidades de discurso extensas, que incluyan tanto la construcción topicalizadora como su antecedente, ya que sobre tal unidad de discurso amplia actuaría el operador existencial que liga simultáneamente a ambos.

La bibliografía sobre análisis del discurso afirma repetidamente que las anáforas nominales aparecen en puntos nodales en el texto, es decir, son marcas de inicio de unidades discursivas (González Ruiz 2010, 138, citando a Conte 1996, Garrido 2013, 107). Esto puede ser cierto para las anáforas nominales definidas, pero no lo es para las anáforas indefinidas que se analizan aquí. Esta estrategia topicalizadora no puede corresponder con un punto nodal en el texto, esto es, no puede considerarse inicio de unidad discursiva, ya que semánticamente necesita el dominio previo para legitimar la variable introducida por el indefinido. Ello implicaría una diferencia más, esta de carácter discursivo, entre las anáforas definidas y las indefinidas, que podría explicar la especialización de estas últimas en cierto tipo de discursos.

Como queda dicho, la estrategia topicalizadora es característica del discurso oral planificado o semi-planificado. Aunque ciertamente aparece en todo tipo de textos, es particularmente querida en los discursos políticos y en los textos periodísticos. Ello no resulta extraño si se piensa que en este tipo de alocuciones es prioritario mantener la atención del oyente o lector, quien difícilmente volverá atrás para comprobar si ha sido capaz de establecer con acierto una relación de correferencia. Lejos de interpretarse como marcas de inicio de unidades discursivas nuevas, los indefinidos anafóricos obligan a interpretar la nueva información como parte integrante de la unidad discursiva previa, y contribuyen, por tanto, a la creación de unidades de discurso más amplias y sostenidas.

\section{Conclusiones}

En este trabajo se ha descrito la estrategia topicalizadora del español que consiste en presentar un tópico discursivo dentro de una estructura bimembre Tópico-Foco, siendo el tópico un grupo nominal indefinido o indeterminado y el foco una oración de relativo restrictiva. Esta estructura supone un reto tanto para los estudios sobre discurso, que limitan el papel de anáforas discursivas 
a los grupos nominales definidos, como para los estudios semánticos, que consideran propiedad inherente de la indefinitud la de introducir nuevos referentes no familiares ni mencionados previamente. La explicación de esta estrategia topicalizadora exige, pues, mirar con detenimiento la interfaz sintaxis-pragmática con el objeto de averiguar qué aspectos sintácticos y semánticos conspiran con los aspectos discursivos para permitir anáforas indefinidas.

Después de describir detalladamente la estrategia topicalizadora utilizando datos reales de su uso discursivo en textos procedentes de las bases de datos CREA y CORPES, se ha propuesto un análisis en el que se encajan los ingredientes sintácticos, semánticos y discursivos de la construcción. Se ha propuesto, en concreto, que la naturaleza nominal de la construcción - esto es, el hecho de que sea un grupo nominal no inserto en una oración matriz- hace que se interprete semánticamente como una variable libre que resulta ligada en el nivel del discurso por el mismo operador existencial no selectivo que liga a su antecedente. Se explica así que un indefinido pueda tener, contra todo pronóstico, valor anafórico. Se ha propuesto igualmente que la oración de relativo restrictiva permite la interpretación de su contenido como focal, lo que no sería posible para una oración de relativo explicativa que modificara a una anáfora discursiva. De ello deriva la posibilidad de que la secuencia sintáctica formada por un grupo nominal indefinido seguido de una oración de relativo restrictiva se interprete informativamente como una estructura bimembre que relaciona un tópico y un foco. Finalmente, se ha propuesto que los requisitos semánticos de la construcción topicalizadora - en concreto, la necesidad de ser ligada por un operador no selectivo del discurso previo - tiene el efecto discursivo de delimitar una unidad de discurso amplia, de manera que la anáfora indefinida no inicia una unidad discursiva nueva, sino que continúa, sin ruptura, la unidad de discurso en que está su antecedente. Esto hace que este recurso topicalizador sea especialmente atractivo cuando el hablante desea mantener una unidad de discurso, como sucede en el discurso oral planificado o semi-planificado.

\section{Agradecimientos}

Agradezco a la editora, y a un dictaminador anónimo, sus comentarios y valiosas observaciones a la primera versión de este trabajo. Sea mi gratitud también para J. Garrido, E. Martínez Caro y T.M. Rodríguez Ramalle por sus observaciones cuando esto no era más que una idea. Cualquier error será, naturalmente, solo de mi responsabilidad. Este trabajo forma parte del proyecto Variación gramatical del español: microparámetros en las interficies sintaxis-sem ántica-discurso (FFI 2017-87140-C4-3-P) financiado por el Gobierno de España. 


\section{Referencias}

Bello, Andrés. 1981 [1847]. Gramática de la lengua castellana destinada al uso de los americanos, ed. R. Trujillo. Tenerife: Cabildo Insular.

Blakemore, Diane. 2011. On the relevance of parentheticals. En Hi-Yon Yoo y Elisabeth DelaisRoussarie (eds.). Actes d'IDP 2009 (Interface Discours et Prosodie), 9-17. Paris: Université Paris-Diderot.

Borreguero, Margarita. 2006. Naturaleza y función de los encapsuladores en los textos informativamente densos (la noticia periodística). Cuadernos de Filología Italiana 13. 73-95.

Bosque, Ignacio. y Gutiérrez-Rexach, Javier. 2009. Fundamentos de gramática formal. Madrid: AKAL.

Brasoveanu, Adrian. y Farkas, Donka. 2016 Indefinites. En Maria Aloni y Paul. Dekker (eds.). The Cambridge Handbook of Formal Semantics, 238-266. Cambridge: Cambridge University Press.

Brucart, Josep M. 1999. La estructura del sintagma nominal. Las oraciones de relativo. En Ignacio Bosque y Violeta Demonte (eds.). Gramática descriptiva de la lengua española, vol. 1, 395-522. Madrid: Espasa Calpe.

Brucart, Josep M. 2016. Oraciones de relativo. En Javier Gutiérrez-Rexach (ed.). Enciclopedia de Lingüística Hispánica, vol. 1, 722-736. London: Routledge.

Burton-Roberts, Noel. 2005. Parentheticals. En Keith Brown (ed.). Encyclopedia of Language \& Linguistics. Oxford: Elsevier.

Conte, Maria-Elisabeth. 1988. Condizioni di coerenza. Ricerche di linguistica testuale. Alessandria: Ediciones del Oso.

Conte, Maria-Elisabeth. 1996. Anaphoric encapsulation. Belgian Journal of Linguistics 10. 1-10.

CORPES, Real Academia Española, Corpus del Español del Siglo XXI. En línea http://www.rae. es. [09-12/2017].

CREA, Real Academia Española, Corpus de Referencia del Español Actual. En línea http://www. rae.es. [09-12/2017].

D’Addio Colosimo, Wanda. 1988. Nominali anaforici incapsulatori: un aspetto della coesione lessicale. En Tullio de Mauro, Stefano Gensini y Maria Emanuela Piemontese (eds.). Dalla parte ricevente: percezione, compressione, interpretazione. Atti del XXVI Convengo Internazionale di Studi della Società di Linguistica Italiana, 143-151. Roma: Bulzoni.

De Cesare, Anna-Maria. 2014. Frequency, Forms and Functions of Cleft Constructions in Romance and Germanic. Contrastive, Corpus-Based Studies, Berlin/Boston: Mouton De Gruyter.

Eguren, Luis y Sánchez López, Cristina. 2003. La gramática de otro. Revista Española de Lingüística 31(1). 69-123.

Eguren, Luis y Sánchez López, Cristina 2004. Contrast and Addition in Romance: A case study on Microvariation. En Julie Auger, J. Clancy Clements y Barbara Vance (eds.).

Contemporary Approaches to Romance Linguistics, 159-176. Amsterdam/Philadelphia: John Benjamins.

Enç, Mürvet. 1991. The semantics of specificity. Linguistic Inquiry 22(1). 1-25.

Farkas, Donka. 1997. Dependent Indefinites. En Francis Corblin, Daniele Godard and JeanMarie Marandin (eds.). Empirical Issues in Formal Syntax and Semantics, 243-267. London: Lang. 
Farkas, Donka. 2002. Specificity Distinctions. Journal of Semantics 19(3). 213-243.

Garrido, Joaquín. 2013. Léxico y argumentación en la estructura del discurso. En Carmen Llamas, Concepción Martínez Pasamar y Manuel Casado (coord.). Léxico y argumentación en el discurso público actual, 105-127. Frankfurt am Main: Lang.

González Ruiz, Ramón. 2010. Gramática y discurso: nominalización y construcción discursiva en las noticias periodísticas. En Concepción Martínez Pasamar (ed.). Estrategias argumentativas en el discurso periodístico, 119-146. Frankfurt am Main: Lang.

Halliday, Michael A.K. y Hasan, Ruqaiya. 1976. Cohesion in English. London: Longman.

Heim, Irene. 1982. The Semantics of Definite and Indefinite Noun Phrases. Tesis de doctorado. University of Massachusetts. Publicada en 1989, New York: Garland.

Kamp, Hans. 1981. A theory of Truth and Semantic Representation. En Jeroen Groenendijk, Theo Janssen y Martin Stokhof (eds.). Formal Methods in the Study of Language. Part 1, 277-322. Amsterdam: Mathematical Center.

Karttunen, Lauri. 1976. Discourse Referents. En James D. McCawley (ed.). Syntax and Semantics Vol. 7, 363-385. New York: Academic Press.

Krifka, Manfred. 2001. Non-novel indefinites in adverbial quantification. En Cleo Condoravdi y Gerard Renardel der Lavalette (eds.). Logical Perspectives on Language and Information, 1-40. Stanford: CSLI Press.

Leonetti, Manuel. 1999. Los determinantes. Madrid: Arco Libros.

Leonetti, Manuel. 2007. Los cuantificadores. Madrid: Arco Libros.

Llamas Sáiz, Carmen. Argumentación en la noticia periodística: el caso de la anáfora conceptual metafórica. En Concepción Martínez Pasamar (ed.). Estrategias argumentativas en el discurso periodístico, 147-160. Frankfurt am Main: Lang.

Moirand, Sophie. 1975. Le rôle anaphorique de la nominalisation dans la presse écrite. Langue Française 28. 60-78.

Moreno Cabrera, Juan Carlos. 1999. Las funciones informativas: las perífrasis de relativo y otras construcciones perifrásticas. En Ignacio Bosque y Violeta Demonte (eds.). Gramática descriptiva de la lengua española, vol. 3, 4245-4302. Madrid: Espasa-Calpe.

Pascual, Rosana y Romero, Daniel. 2016. Un caso de cambio categorial: los relativos como marcadores de discurso. En Nora Múgica (ed.). En torno a las interfaces del lenguaje en la lingüística generativa, 118-143. Bahía Blanca: Ed. de la Universidad Nacional del Sur.

Pecorari, Filippo. 2014. Anaphoric encapsulation and presupposition: persuasive and stereotypical uses of a cohesive strategy. Cadernos de Letras da UFF - Dossiê: Anáfora e correferência: temas, teorias e métodos 49.175-195.

Sánchez López, Cristina. 1999. Los cuantificadores: Clases de cuantificadores y estructuras cuantificativas. En Ignacio Bosque y Violeta Demonte (eds.). Gramática descriptiva de la lengua española, vol. I, 1025-1128. Madrid: Espasa-Calpe.

Suñer, Avelina. 1999. La aposición y otras relaciones de predicación en el sintagma nominal. En Ignacio Bosque y Violeta Demonte (eds.). Gramática descriptiva de la lengua española, vol. I, 523-564. Madrid: Espasa-Calpe. 
